\title{
NMR Studies of Lignins. 5. Investigation of Non-derivatized Spruce and Birch Lignin by ${ }^{1} \mathrm{H}$ NMR Spectroscopy
}

\author{
KNUT LUNDQUIST
}

Department of Organic Chemistry, Chalmers University of Technology and University of Göteborg, S-412 96 Göteborg, Sweden

Non-derivatized milled wood lignins from spruce (Picea abies) and birch (Betula verrucosa) have been examined by ${ }^{1} \mathrm{H}$ NMR spectroscopy, using a 270 $\mathrm{MHz}$ instrument. The results confirm and complement structural information obtained in previous ${ }^{1} \mathrm{H}$ NMR studies with acetylated lignins.

The lignins were found to contain only a few units with a noncyclic benzyl aryl ether linkage (spruce, $<3 \%$; birch, $\approx 5 \%$ ). The number of cinnamyl alcohol units was small $(<1 \%)$. Signals from $\beta-1$ structures could not be detected, and it is suggested that such structures exist in a masked form in the lignins. Support was obtained for the occurrence of units with a methylene group.

${ }^{1} \mathrm{H}$ NMR examinations of milled wood lignins from spruce (Picea abies) and birch (Betula verrucosa) have been described in previous papers ${ }^{1}$ in this series. The lignins have primarily been examined as acetate derivatives in deuteriochloroform solutions. Some results from studies of non-derivatized lignins dissolved in dioxane- $d_{8}-\mathrm{D}_{2} \mathrm{O}(5: 1)$ have, however, also been reported. This paper summarizes the structural information obtained from ${ }^{1} \mathrm{H}$ NMR studies of solutions of non-derivatized spruce and birch lignins in dioxane- $d_{8}-\mathrm{D}_{2} \mathrm{O}$ (5:1). Model compound data reported earlier, ${ }^{1 \mathrm{a}, \mathrm{c}}$ together with those given in Table 1, provided a basis for interpretations of the spectra. Spruce lignin consists almost entirely of guaiacyl units, while birch lignin consists of nearly equal amounts of guaiacyl and syringyl units. Model compound data which elucidate the influence of aromatic groups of the syringyl type on the position of signals from side chain protons are, however, insufficient. Therefore, the assignments of some of the signals in the birch lignin spectrum are uncertain.
Spruce lignin. The spectrum of spruce lignin is shown in Fig. 1. Peak positions and an interpretation of the spectrum are given in Table 2. Model compound data suggest that the peak at $\delta 2.59$ is due to $\beta-\beta$ structures of type $A(13)$ rather than 3,4divanillyltetrahydrofuran $(8)$ incorporated in the lignin ( $c f$. Ref. 1d). The broad peak around $\delta 1.80$ (Fig. 1) is probably in part caused by signals from $\mathbf{H}_{\beta}$ in structures of type 13 . Degradation products with 3-hydroxypropyl side chains have been obtained on hydrolysis of wood at $180^{\circ} \mathrm{C}^{2}$ If such side chains are present in the original lignin, they will contribute to the signals at $\delta 2.59$ and 1.80 (footnote $b$ in Table 1). Calculated as methylene groups, the peak at $\delta 2.59$ was estimated to correspond to $2 \%$ of the side chains. No signal which could be attributed to $\beta-\beta$ structures of type B could

Table 1. NMR data for side chain protons in model compounds $1-8$ [solvent, dioxane- $\left.d_{8}-\mathrm{D}_{2} \mathrm{O}(5: 1)\right]$.

\begin{tabular}{lll}
\hline Compound & \multicolumn{2}{l}{$\begin{array}{l}\delta \text { Value; } J \text { values in } \mathrm{Hz} \text { are given } \\
\text { in parentheses }\end{array}$} \\
\cline { 2 - 3 } & $\mathrm{H}_{\alpha}$ & $\mathrm{H}_{\beta}$ \\
\hline $1^{a}$ & $6.49(16)$ & $6.23(5.5,16)$ \\
2 (erythro form) & $5.30(6.3)$ & $4.55(\mathrm{~m})$ \\
$3^{b}$ & $5.46(6.5)$ & \\
4 & $5.49(6.5)$ & $2.96(\mathrm{~m})$ \\
5 (threo form) & $4.78(8.5)$ & $2.87(\mathrm{~m})$ \\
$6($ erythro form) & $4.89(5.5)$ & $1.86(\mathrm{~m})$ \\
7 & $2.59^{c}$ & \\
8 & $2.46(8,14)^{d}$ & $2.14(\mathrm{~m})$ \\
& $2.57(6,14)^{d}$ & \\
\hline
\end{tabular}

${ }^{a} \delta\left(\mathrm{H}_{\gamma}\right)=4.16(J=5.5 \mathrm{~Hz}) .^{b} \delta\left(\mathrm{H}_{\alpha^{\prime}}\right)=2.58, \delta\left(\mathrm{H}_{\beta^{\prime}}\right)=1.80$. ${ }^{c} 2 \mathrm{H}$, doublet $(J=7 \mathrm{~Hz}){ }^{d} 1 \mathrm{H}$. 


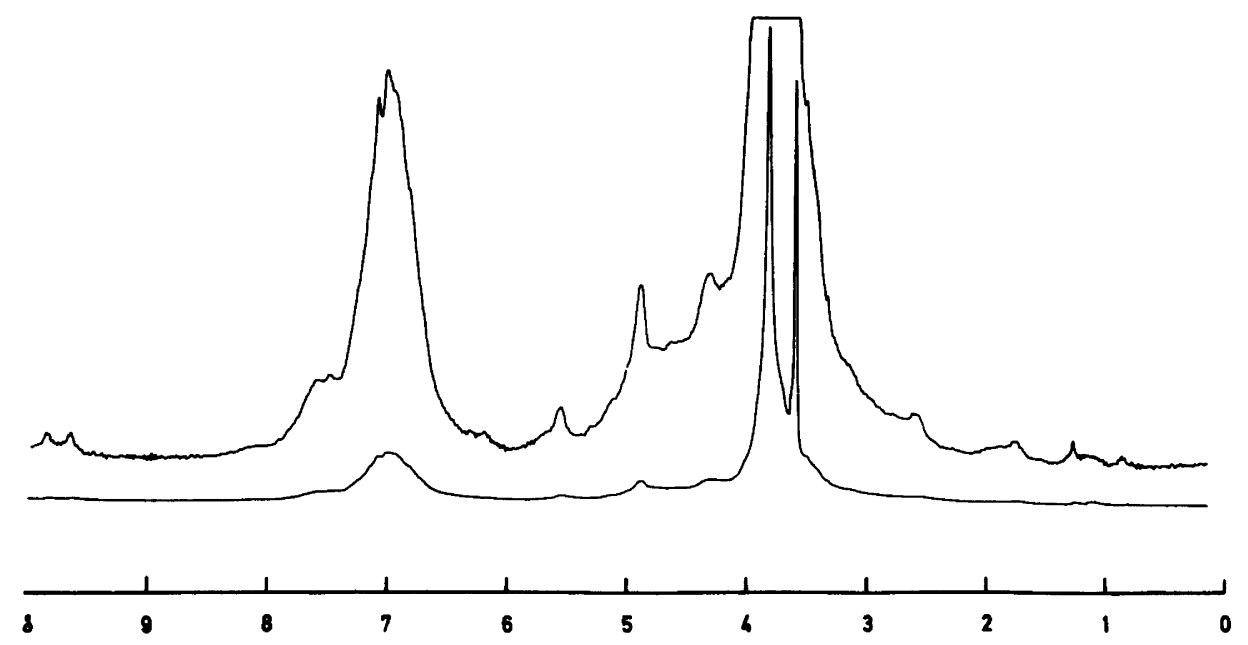

Fig. 1. ${ }^{1} \mathrm{H}$ NMR spectrum of milled wood lignin from spruce. For peak positions and interpretation, see Table 2. (No internal standard was present, and the signal from dioxane $(\delta 3.58)$ is used to indirectly relate signal positions to the internal standard.)

be detected $\left[\delta 3.06\left(\mathrm{H}_{\beta}\right)\right.$ and $\left.4.71\left(\mathrm{H}_{\alpha}\right)\right]$. The signal from $\mathrm{H}_{\alpha}$ in $\alpha-\mathrm{O}-4$ structures of type 10 could be expected to appear at $\delta 5.30$ (Table 1). The absence of any distinct signal in the region around $\delta 5.30$ (an inflexion or a small peak (Fig. 1) at $\delta 5.26$ could

Table 2. Assignments of signals in the ${ }^{1} \mathrm{H}$ NMR spectrum of spruce lignin (Fig. 1). Several peaks are broad and have irregular shapes; $\delta$ values given always refer to the highest point of the peak.

\begin{tabular}{|c|c|}
\hline$\delta$ Value/ppm & Assignment \\
\hline 2.59 & $\begin{array}{l}\text { Methylene protons in } \beta-\beta \\
\text { structures of type } A(13)\end{array}$ \\
\hline 3.58 & Dioxane (solvent) \\
\hline 3.80 & $\begin{array}{l}\text { Hydroxyl protons (protons in } \\
\text { methoxyl groups, } \mathbf{H}_{\gamma} \text { in various } \\
\text { types of structures) }\end{array}$ \\
\hline 4.30 & $\mathrm{H}_{\beta}$ in $\beta-O-4$ structures $(9)$ \\
\hline 4.86 & $\mathrm{H}_{\alpha}$ in $\beta-\mathrm{O}-4$ structures $(9)$ \\
\hline 5.51 & $\mathrm{H}_{\alpha}$ in $\beta-5$ structures (11) \\
\hline 6.15 & Unknown \\
\hline 6.27 & $\mathrm{H}_{\beta}$ in cinnamyl alcohol units (15) \\
\hline 6.95 & Aromatic protons \\
\hline 7.03 & Aromatic protons \\
\hline 7.42 & Aromatic protons \\
\hline 9.54 & $\begin{array}{l}\text { Formyl protons in cinnamaldehyde } \\
\text { units }\end{array}$ \\
\hline 9.75 & $\begin{array}{l}\text { Formyl protons in benzaldehyde } \\
\text { units }\end{array}$ \\
\hline
\end{tabular}

Table 3. Assignment of signals in the ${ }^{1} \mathrm{H}$ NMR spectrum of birch lignin (Fig. 2). Several peaks are broad and have irregular shapes; $\delta$ values given always refer to the highest point of the peak.

\begin{tabular}{ll}
\hline$\delta$ Value/ppm & Assignment \\
\hline 0.57 & Internal reference $\left(\mathrm{C}-\mathrm{CH}_{2}-\mathrm{Si}\right)$ \\
1.72 & Internal reference $\left(\mathrm{C}-\mathrm{CH}_{2}-\mathrm{C}\right)$ \\
2.74 & Internal reference $\left(\mathrm{C}-\mathrm{CH}_{2}-\mathrm{S}\right)$ \\
3.05 & $\mathrm{H}_{\beta}$ in $\beta-\beta$ structures of type $\mathrm{B}(14)$ \\
3.58 & Dioxane (solvent) \\
3.78 & Protons in methoxyl groups \\
3.87 & $\mathrm{Hydroxyl}$ protons \\
4.13 & $\mathrm{H}_{\beta}$ in $\beta-\mathrm{O}-4$ structures ${ }^{a}(9)$ \\
4.71 & $\mathrm{H}_{\alpha}$ in $\beta-\beta$ structures of type $\mathrm{B}(14)$ \\
4.92 & $\mathrm{H}_{\alpha}$ in $\beta$-O-4 structures $(9)$ \\
5.22 & $\mathrm{H}_{\alpha}$ in noncyclic benzyl aryl ethers \\
& $(10)$ \\
5.50 & $\mathrm{H}_{\alpha}$ in $\beta-5$ structures $(11)$ \\
5.99 & Unknown \\
6.24 & $\mathrm{H}_{\beta}$ in cinnamyl alcohol units (15) \\
6.73 & Aromatic protons \\
6.98 & Aromatic protons \\
9.56 & Formyl protons in cinnamaldehyde \\
9.77 & units \\
& Formyl protons in benzaldehyde \\
& units \\
\hline
\end{tabular}

${ }^{a}$ Assignment uncertain due to insufficient model compound data. 

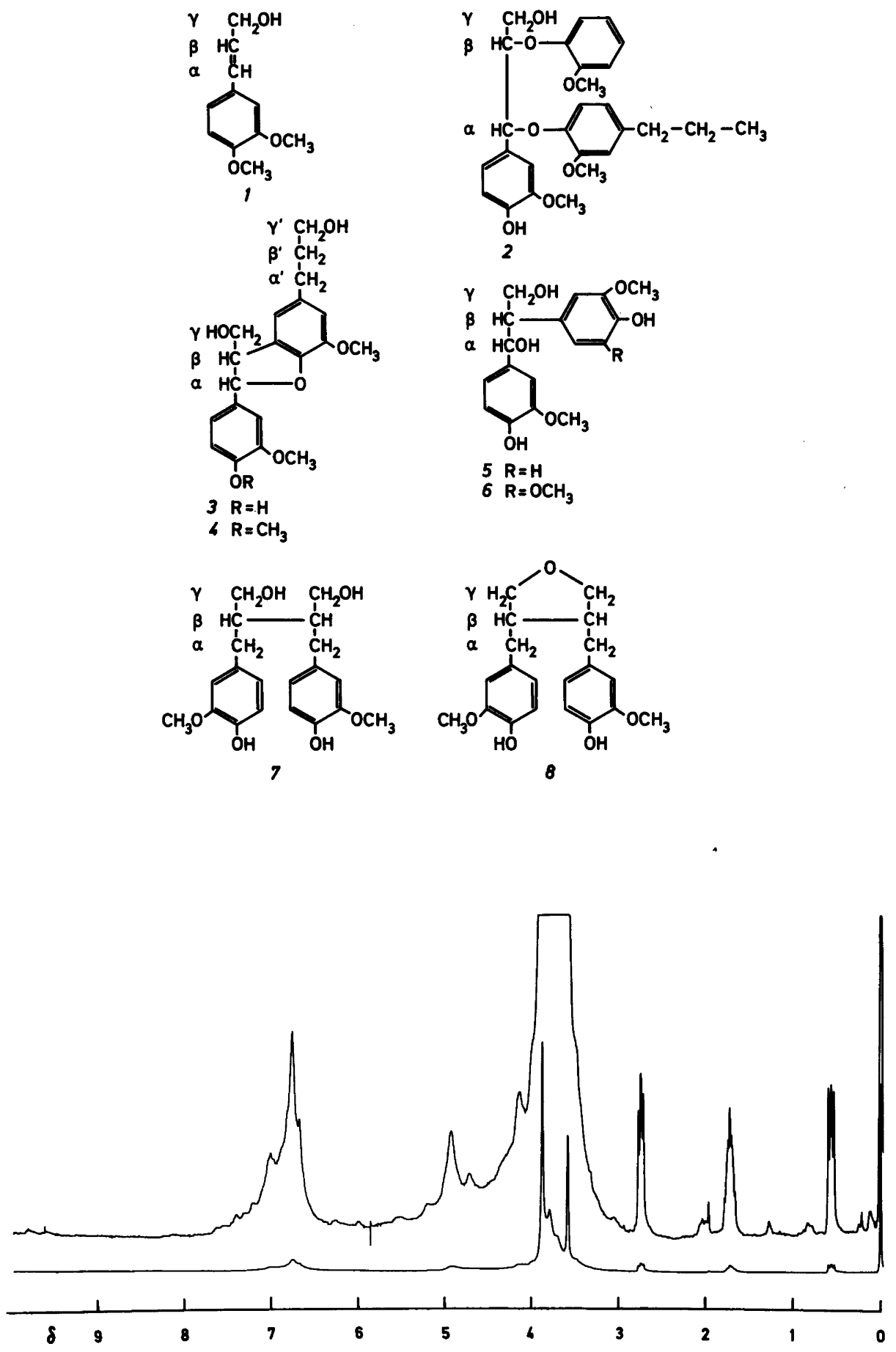

Fig. 2. ${ }^{1} \mathrm{H}$ NMR spectrum of milled wood lignin from birch. For peak positions and interpretation, see Table 3.

Acta Chem. Scand. B 35 (1981) No. 7 


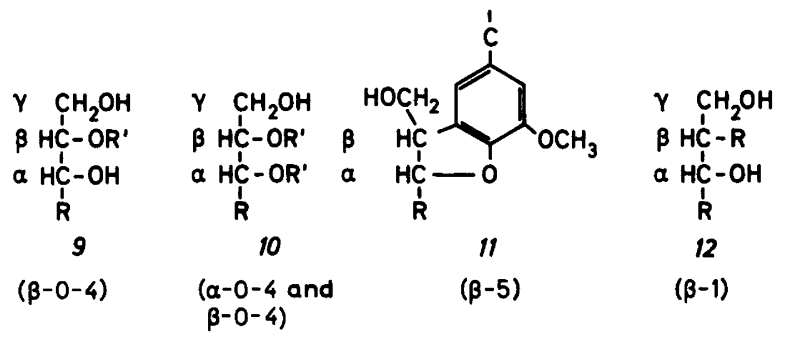

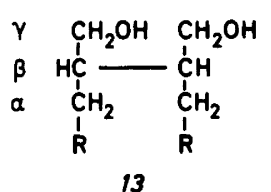

$(\beta-\beta$, type $A)$

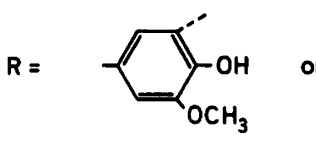<smiles>[R]C1OC2COC3C([R])C1C23</smiles>

$(\beta-\beta$, type $B)$<smiles>[R]C=CCO</smiles>

15

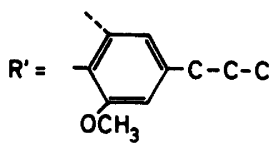

be discerned in the spectra) is interpreted as indicating that at most a small proportion $(<3 \%)$ of the units has structure 10 . Examinations of acetylated lignin ${ }^{1 \mathrm{~d}}$ together with recent model compound studies ${ }^{3}$ similarly suggest only a small number of structures of type 10 . The small peak at $\delta 6.27$ may be due to $\mathrm{H}_{\beta}$ in cinnamyl alcohol units (15); obviously the number of such units is very small $(<1 \%)$. The occurrence of $\beta-1$ structures (12) should give rise to a separate signal at about $\delta 2.90\left(\mathrm{H}_{\beta}\right)$. However, no signal could be detected in the region around this $\delta$ value in the spruce lignin spectrum. Studies on lignin degradation products provide strong evidence for the occurrence of $\beta-1$ structures in lignins. Therefore, the absence of signals which could be attributed to such structural elements is interpreted as indicating that $\beta-1$ structures exist in a masked form in the lignin (e.g., as cyclohexadienone structures of the type previously suggested $^{4}$ ).

Birch lignin. The spectrum of birch lignin is shown in Fig. 2. Peak positions and an interpretation of the spectrum are given in Table 3. The peak at $\delta 5.22$ is possibly caused by $\mathrm{H}_{\alpha}$ in noncyclic benzyl aryl ethers (10). Calculated as units of type 10 , this peak corresponds to about $5 \%$ of the side chains. The peak at $\delta 5.50$ can be attributed to $\mathrm{H}_{\alpha}$ in $\beta-5$ structures (11) and corresponds to approximately $5 \%$ of the units. A very small peak at $\delta 6.24$ can be attributed to $\mathbf{H}_{\beta}$ in cinnamyl alcohol units; ap- parently the amount of such units is small $(<1 \%)$. Signals which could be attributed to $\beta-1$ structures were not detected ( $c f$., the above discussion of the occurrence of $\beta-1$ structures (12) in spruce lignin). Runs with no internal standard added revealed the occurrence of some very weak signals in the range of $\delta 0-3$, which conceivably were caused by side chain protons in $\beta$ - $\beta$ structures of type A (13).

Derivatization of lignins may cause unwanted chemical modification or may be incomplete. Sources of errors influencing results from ${ }^{1} \mathrm{H}$ NMR studies of acetylated lignins are presently under investigation. Non-derivatized lignins differ unfavourably from lignin acetates in the respect that signals from the side chain protons are found in a fairly narrow range located around $\delta 4$. This hampers an interpretation in structural terms, although as it appears from the preceding sections, certain structural questions favourably could be elucidated by examination of non-derivatized lignins.

In a study of the solvent dependence of peak positions (non-derivatized lignin), it was found that peak positions largely agreed with those obtained when dioxane - water was used as a solvent. However, it was found that with a mixture of pyridine and acetic acid (1:1), a somewhat better resolution of the signals from side chain protons was obtained. Thus, the methoxyl proton signal was found at $\delta$ 3.81 , while the signal from $\mathrm{H}_{\alpha}$ in $\beta-\mathrm{O}-4$ structures 
(9) was found at $\delta 5.27$ (the signal from hydroxyl protons appeared at about $\delta 12$ ).

\section{EXPERIMENTAL}

${ }^{1} \mathrm{H}$ NMR spectra were recorded with a $270 \mathrm{MHz}$ instrument working in the pulse Fourier mode (Bruker WH 270). Dioxane- $d_{8}-\mathrm{D}_{2} \mathrm{O}(5: 1)$ or pyridine- $d_{5}-\mathrm{CD}_{3} \mathrm{COOD}(1: 1)$ was used as a solvent. The sodium salt of 3-(trimethylsilyl)propane sulfonic acid was used as an internal reference. The temperatures were about $300 \mathrm{~K}$. Excepting the signals from hydroxyl protons, peak positions were found to be practically unaffected by minor variations in the temperature.

Acknowledgements. Thanks are due to Prof. T. Higuchi, Kyoto, for a gift of compound 2. The author also thanks Dr. D. Robert, Grenoble, for stimulating discussions and for communicating some results from ${ }^{1} \mathrm{H}$ NMR studies of lignins in DMSO solution.

\section{REFERENCES}

1. a. Lundquist, K. and Olsson, T. Acta Chem. Scand. B 31 (1977) 788; b. Lundquist, K. Acta Chem. Scand. B 33 (1979) 27; c. Lundquist, K. Acta Chem. Scand. B 33 (1979) 418; d. Lundquist, K. Acta Chem. Scand. B 34 (1980) 21.

2. Klemola, A. Suom. Kemistil. B 41 (1968) 83; Sakakibara, A. Wood Sci. Technol. 14 (1980) 89.

3. Brunow, G. and Lundquist, K. Unpublished data.

4. Lundquist, K., Miksche, G. E., Ericsson, L. and Berndtson, L. Tetrahedron Lett. (1967) 4587.

Received April 2, 1981. 